\title{
APPRAISAL OF WESTERN HEMLOCK LOOPER INFESTATIONS ${ }^{1}$
}

\section{By M. G. THOMSON 2}

M. G. Thomson was born in Vancouver, B.C., in 1922. He joined the Forest Biology Laboratory, Victoria, B.C., in 1946 after serving in the Armed Forces. He received a B.S.A. degree (U.B.C.) in 1947 and a M.Sc. degree (U. California) in 1949. He is at present registered for a Ph. D. degree in Forest Entomology at U.B.C. He is currently chairman of the Western Forest Insect Work Conference.

Most of the major defoliating insects in Canada are present in a stand in epidemic proportions a year or more before serious tree mortality results. This allows time for the detection, surveying, and assessment of these outbreaks and the orderly planning of control measures, where necessary. Several geometrids, notably the western hemlock looper, Lambdina fiscellaria lugubrosa (Hulst), are exceptions. In the past, there have been numerous cases in which western hemlock looper outbreaks have been discovered within several weeks of severe defoliation that resulted in heavy tree mortality. For this reason it is essential that an adequate appraisal of the situation be made as soon as outbreaks of this insect, hereafter referred to as the looper, are discovered. Some information which may assist in such an appraisal is presented here.

Incipient looper outbreaks can be detected with adequate ground surveys by trained personnel during either the egg or larval stages in the year prior to severe defoliation. These populations can easily be missed, however, by those not familiar with the species. An approaching outbreak may also be indicated if large brown moths are abundant in an area during the autumn, since the adult looper is usually fairly common during the September and October prior to an outbreak.

The moth has tan wings mottled with grey. The wing span is approximately one to one and one-quarter inches. Two irregular dark lines divide the front wing roughly into thirds. Between the lines, near the leading edge of the wing, there is a dark spot. There is an orange line on the outside of the outer and one on the inside of the inner line, and touching them. There is only one set of lines on the rear wings, contiguous with the outer lines of the front wings.

The Annual Reports of the Forest Insect Survey for 1944 and 1953, the years prior to each of the two most recent looper outbreaks, give an indication of the type of warning given by this insect. In 1944, adults were common in a number of southern coastal areas and on the west side of the Big Bend, but no larvae had been received by the survey. The looper populations were at a low ebb during the years immediately preceding.

The following year, 1945, extensive damage was caused by the looper to stands south of the Alberni Canal on Vancouver Island, on the north side

\footnotetext{
${ }^{1}$ Contribution No. 341, Forest Biology Division, Science Service, Department of Agriculture, Ottawa, Canada. Accepted for publication November 12, 1956.

"2 Forest Biology Laboratory, Victoria, B.C.
} 
of the Fraser River and adjacent to Howe Sound on the lower mainland, and from Wells Gray Park through to the Arrow Lakes in the interior wet belt.

From 1950 to 1953 only a small proportion of the samples received by the survey contained loopers. Positive collections usually contained only one or two larvae, but there was a gradual increase in the number of such collections each year. In 1953, the loopers were notably numerous in one area where six collections from hemlock-cedar stands averaged 55 larvae, but defoliation was not noticeable. In 1954, the species reached outbreak proportions that caused heavy defoliation in several adjacent areas, and there was a considerable increase in population levels throughout the province.

During an outbreak year, defoliation in the stand normally will only show within the last two to three weeks of feeding. Thus, if an infestation is first detected from the defoliation, there is little time to arrange for a control operation. If equipment is available on short notice, however, such an operation may be possible since each infestation usually is localized initially.

When a looper infestation is detected from defoliation, the following information should be obtained immediately:

1. Identification of the insect.

2. Nature and severity of the defoliation.

3 . Extent of the infestation.

4. Stage of development of the larval population.

5. Presence of parasites or disease.

IDENTIFICATION OF THE INSECT

In view of the difference in the rate at which the western hemlock looper and other defoliators can damage a stand, it is important that the insect causing the defoliation be identified.

The following brief description will assist in eliminating many species which are not the looper. The western hemlock looper is only one of a great number of geometrids or loopers. All are characterized by having "feet" at the back end as well as next to the head and move by drawing the rear "feet" up to the front ones, then extending the front ones-hence the name. The western hemlock looper is found mainly on coniferous trees. In the later instars, when defoliation would be apparent, the larvae are covered by a complex linear and transverse pattern in shades of brown and/or grey and there are two pairs of dark spots on the top of each abdominal segment (1). The larva of an insect causing similar damage, the phantom hemlock looper, Nepytia phantasmaria (Stkr.), is bright green and has two pale yellow lines with dark edges on each side. In Canada positive identification may be obtained by sending living specimens to the nearest Forest Biology Laboratory.

\section{Nature and Severity of the Defoliation}

In order to assess the danger to the stand and the need for control, it is necessary to determine the amount of defoliation at the time of detection. It will be pointed out later how an estimate of total defoliation can be made from this. This estimate can be used to assess possible mortality.

The assessment of defoliation should take into account the percentage 
defoliation for each crown class for each of the tree species present, and the variation in degree of defoliation within the crowns. These estimates should be used to arrive at an over-all estimate of the total foliage in the crown destroyed at the time of the examination. This has been caused by the feeding up to that time. When this figure is multiplied by the proportion of feeding anticipated, it will give an estimate of the maximum defoliation that may be expected during the current season.

In past outbreaks heavy defoliation showed first in isolated trees and on those at the edge of the stand. At the same time there was a general thinning of the tips and upper crown within the stand. Where populations were large, this soon changed to marked defoliation throughout the crowns.

\section{EXTENT OF THE INFESTATION}

The extent of the infestation can be determined rapidly from the air when the defoliation is evident, or from the ground by the defoliation or by the large number of larvae which drop when small trees within the stand are shaken.

\section{Stage of Development of the Larval Population}

The looper larvae go through five feeding stages or instars. By determining the proportion of the population in each of the instars it is possible to estimate the amount of feeding that is still to occur and, therefrom, the extent of the final defoliation. For those unfamiliar with the species, a gross description of the various instars will be helpful.

The most accurate way for those unfamiliar with the species to distinguish the instars is to measure the head capsule width, since each instar has a characteristic head size. As this, however, is seldom practical in the field, less precise means will usually have to suffice. Typical measurements for each instar are shown in Table 1.

TABLE 1.

LaRVal MEasurements

\begin{tabular}{|c|c|c|c|c|}
\hline Instar & $\begin{array}{r}\text { Head Capsule } \\
\text { Average } \\
\end{array}$ & $\begin{array}{r}\text { Width (MM) } \\
\text { Range }\end{array}$ & $\begin{array}{c}\text { Average b } \\
\text { (MM) }\end{array}$ & $\begin{array}{c}\text { ody length } \\
\text { (Inches) }\end{array}$ \\
\hline First (I) & 0.42 & - & 5 & 0.2 \\
\hline Second (II) & 0.68 & $0.61-0.73$ & 8 & 0.3 \\
\hline Third (III) & 1.03 & $0.94-1.12$ & 12 & 0.5 \\
\hline Fourth (IV) & 1.53 & $1.39-1.74$ & 17 & 0.7 \\
\hline Fifth (V) & 2.02 & $1.84-2.24$ & 30 & 1.2 \\
\hline
\end{tabular}

A more rapid, although less certain, method is to use the general coloration and the head-width, body-width ratio. The first-instar body is very small and covered with alternating light and dark grey rings. In the second instar, these bands are attentuated and masked by the yellow-brown color of the gut contents. In the third instar the lateral lines and the sets of four dorsal dots become more prominent and the body has a denser, less translucent appearance. The head capsule is black during the first three instars. In the third instar, the epicranial suture, an inverted ' $\mathrm{Y}$ ' shaped line, is prominent. The markings 
of the fourth- and fifth-instar larvae were described above. The head capsule is mottled in the fourth instar, and light grey with approximately four pairs of prominent round dark spots in the fifth. When there is doubt as to which of two instars a larva is in, it can usually be resolved by the head-width, bodywidth ratio. At the start of an instar the head is noticeably wider than the body. At mid-instar both are equal. Towards the end of an instar the head appears to be encircled by the swollen thorax.

During the first two instars, feeding is restricted to the newly-opened buds. From the third instar on, foliage of all ages is attacked. The insect is a wasteful feeder, usually eating only a small portion of one side of a given needle and then moving on to another one. For this reason it causes far greater damage for a given amount of feeding than do other species which consume the major portion of needles attacked.

In addition, the loopers are extremely motile. In 1954, larvae were placed on a small tree in a stand opening and their activity and movement followed continuously during daylight for a two-week period. Under the various weather conditions encountered, the population was constantly shifting. In general, the greatest number were found in that portion of the tree nearest the sun and each day the population moved completely around the tree. There was also considerable vertical movement, especially in the early morning when many larvae dropped on threads. Much of the feeding appeared to take place at night.

The tendency to frequent sunlit branches at temperatures encountered in outbreak areas accounts for the early defoliation of isolated trees and the upper crowns. The continuous movement throughout the crown helps to explain the small portion of the damaged needles actually consumed, and the widespread and rapid nature of the defoliation.

In 1948 a linear regression between the dry body weight of an insect and the total production of solid excrement or frass was established (3). Forty larvae, randomly selected, used in this study completed their larval development. Each was reared individually and its frass was collected at fourto five-day intervals. The combined frass production accumulated for each interval is compared with the stage of development in Figure 1. The percentage of insects in each instar on a given day is indicated by a series of curves on the bottom of the chart and the percentage of total feeding, as indicated by frass production, is shown by the broad S-shaped curve. Although based on insectary-reared larvae, the shapes of the instar curves are very similar to those obtained in outbreak areas by field sampling during 1946 and 1947.

The drop in the right-hand fifth-instar curve is associated with the cessation of feeding and the onset of pupation. In the field, this point may be recognized when there are no more fourth-instar larvae in the sample or when pupae or prepupae are found.

When a looper outbreak is first discovered while feeding is in progress, an estimate of the total amount of defoliation that may be expected may be obtained as follows:

Locate the position of a vertical line on Figure 1 which intersects the instar curves at points which most closely correspond to the proportions of 


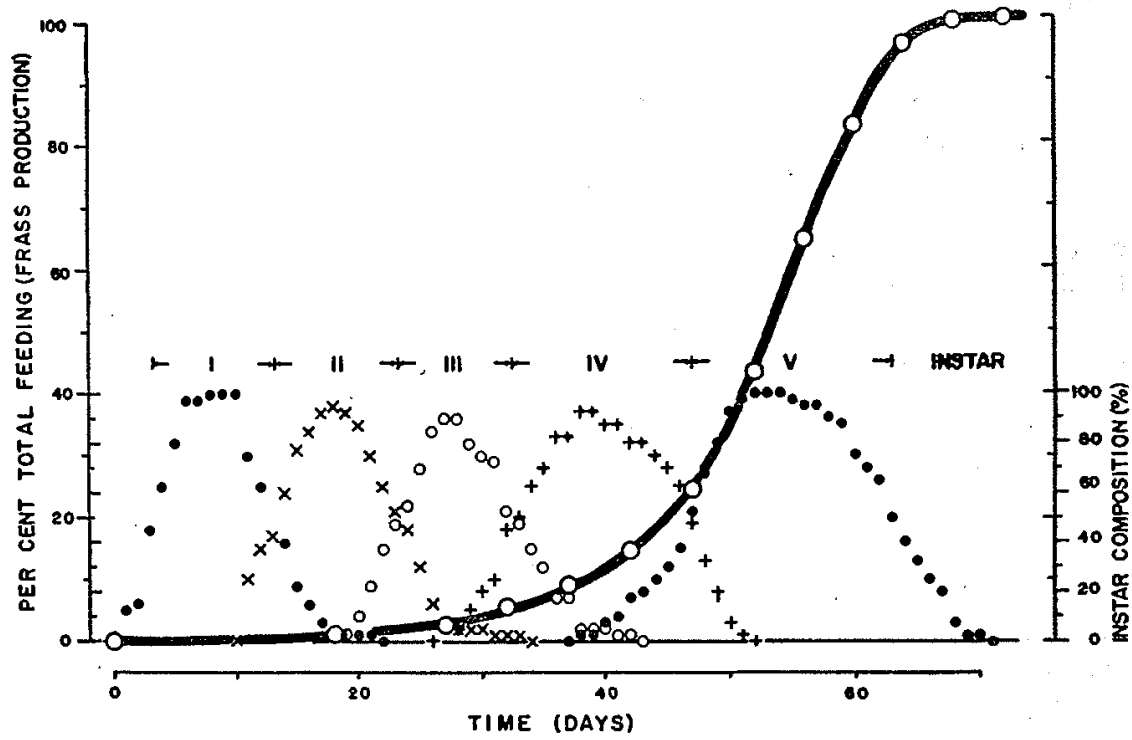

FIGURE 1. Proportion of total "feeding by stage of development.

each instar found in the sample. Where this line intersects the heavy line, extend a horizontal line to the left and read off the per cent total feeding. This will give an estimate of the proportion of the total feeding that has already taken place, assuming that there is no further larval mortality. For example, if the sample at the time the infestation was discovered contained 5 per cent third-instar, 80 per cent fourth-instar and 15 per cent fifth-instar larvae and the average defoliation of the stand for the entire crown was 10 per cent, then the anticipated final defoliation would be $10 \times \frac{100}{15}=67$ per cent, assuming that there was no further larval mortality.

The graph can also be used to obtain a rough indication of the time available to organize a control program. It is the writer's opinion that chemical control operations are impractical after the mid-fifth instar has been reached, since the rate of defoliation is then so rapid that little protection can be gained.

The relation between defoliation and subsequent tree mortality in stands attacked during the 1945 to 1947 outbreak on southern Vancouver Island (2) may be used to anticipate the possible effect of the outbreak if uncontrolled. The expected mortality can be calculated by multiplying the product of the volume per tree and the proportion of foliage lost by the appropriate coefficient below. If current inventories are available, the operation can be simplified by multiplying the product of the volume per acre and the estimate of average defoliation of each species by the appropriate coefficient. 
The mortality coefficients for even-aged hemlock stands-either pure, with Douglas fir or amabilis fir are:

$$
\begin{aligned}
& \mathrm{M}_{\mathrm{H}}=0.934\left(\mathrm{~B}_{\mathrm{H}} \mathrm{P}_{\mathrm{H}}\right) \\
& \mathrm{M}_{\mathrm{F}}=1.039\left(\mathrm{~B}_{\mathrm{F}} \mathrm{P}_{\mathrm{F}}\right) \\
& \mathrm{M}_{\mathrm{B}}=2.380\left(\mathrm{~B}_{\mathrm{B}} \mathrm{P}_{\mathrm{B}}\right)-0.749\left(\mathrm{~B}_{\mathrm{B}}\right)-1.547\left(\mathrm{P}_{\mathrm{B}}\right)
\end{aligned}
$$

where $M$ is the sum of the basal area of dead trees in square feet, $B$ is the sum of the basal area of the trees before the outbreak and $P$ is the sum of the proportions of defoliation. BP is the sum of the basal area times proportion of defoliation of each tree. The subscripts $\mathrm{H}, \mathrm{F}$, and $\mathrm{B}$ refer to western hemlock, Douglas fir, and amabilis fir respectively. In all-aged hemlock stands:

$$
\mathbf{M}_{\mathrm{H}}=0.473\left(\mathrm{~B}_{\mathrm{H}} \mathbf{P}_{\mathrm{H}}\right)
$$

and there was no Douglas fir mortality. For example, if the infestation previously used as an illustration occurred in an even-aged stand of hemlock running 10,000 cubic feet to the acre, then the anticipated mortality if no control was undertaken would be

$$
\mathrm{M}_{\mathrm{H}}=0.934 \times 10,000 \times 67 / 100=6,258 \mathrm{cu} \text {. ft. } / \text { Ac. }
$$

\section{Presence of Parasites or Disease}

Where the parasite populations are very high, or where disease is present, there will be heavy larval mortality and, as a result, a marked reduction in the total feeding and defoliation from the estimates. The effects of parasites and disease on the larval population are normally most marked during the fifth instar, at the time the major part of the feeding occurs. It is usually very difficult, however, to measure the effectiveness of these factors until after feeding has been completed.

\section{Discussion}

This paper is intended to point up to agencies responsible for protection of timber the need for early detection of looper infestations and to indicate what information is necessary to appraise an outbreak of this insect when it is discovered. Because tree-killing defoliation can occur in the year the infestation is first detected, it is essential that the information necessary to decide for or against a control program be obtained as simply and as quickly as possible. The information recommended here fills these requirements and, when used in conjunction with Figure 1 and with results on stand defoliation and tree mortality previously published (2), should permit a sound decision to be made. Considerably more time, which is not usually available, would be required to obtain any significant refinement in the accuracy of the appraisal.

Chemical control, if applied before the start of the last instar, should provide a considerable amount of protection to a stand even during very heavy outbreaks, but if delayed until the middle of the last instar, it would have very little influence on preventing serious defoliation. Earlier control is desirable. Where time does not permit the organizing of a chemical control program, or where timber values or the cutting program do not warrant the cost of a control operation, the immediate logging of the infested stands should be considered. Early removal of heavily defoliated trees will lessen or prevent losses through secondary beetle attack, rot, or breakage. In addition, if the logs are removed before the next spring, it will help to reduce the 
looper population in the area since most of the eggs are laid in the moss or crevices on the bark.

A watch should be kept for looper infestations in 1957, since several outbreaks of the phantom hemlock looper occurred in the vicinity of Vancouver in 1956, and there have been several western hemlock looper outbreaks in the northeastern part of British Columbia during the past few years.

\section{REFERENCES}

1. EVANS, D. 1954. Larval colour key to some of the common species of forest Geometridae of the British Columbia Coast. Interim Tech. Rept., Forest Biology Laboratory, Victoria, B.C.

2. KINGHORN, J. M. 1954. The influence of stand composition on the mortality of various conifers, caused by defoliation by the western hemlock looper on Vancouver Island, British Columbia. For. Chron, $30(4): 380-400$.

3. THOMSON, M. G. 1949. The determination of larval populations of forest defoliators by frass fall and body weight. M. Sc. Thesis, University of California, Berkeley, Calif. 